Apr 2016, Volume 1, Issue 1 (18 - 19)

\title{
Acute Myocardial Infarction in a Patient With Elevated ST-Segment in aVR Lead and Diffuse ST Segment Depression in Other Leads: A Case Report
} \author{
Morteza Safi ${ }^{1}$, Isa Khaheshi ${ }^{1,}$, , Mehdi Memaryan ${ }^{1}$ \\ ${ }^{1}$ Cardiovascular Research Center, Shahid Beheshti University of Medical Sciences, \\ Tehran, Iran. \\ * Corresponding author: Isa Khaheshi, Cardiovascular Research Center, Shahid \\ Beheshti University of Medical Sciences, Tehran, Iran. Tel: +98-9125441637, E-mail: \\ isa_khaheshi@yahoo.com
}

DOI: $10.20286 /$ ijcp-010102

Submited: 12.09 .2015

Accepted: 02.09.2015

\section{Keywords:}

ST Elevation; aVR

Arteries

Myocardial Infarction

(C) 2016. International Journal of

Cardiovascular Practice.

\begin{abstract} performed for the patient.
\end{abstract}

ST elevation in aVR in conjunction with diffuse ST depression in precordial leads may indicate occlusion of very proximal portion of the left anterior descending artery. We present a 54-year old man, with crushing retrosternal pain and ST-segment elevation only in aVR lead and diffuse ST-segment depression in inferior, lateral and precordial leads. The patient was scheduled for emergent coronary angiography, which showed that left anterior descending (LAD) artery was cut off at very proximal portion and urgent CABG was

\section{INTRODUCTION}

ST elevation in aVR lead has precise significance in ECG interpretation. This finding could be supportive in diagnosis of myocardial infarction due to left main coronary artery occlusion. However, this finding may be overlooked in emergency units, particularly in the absence of ST segment abnormalities like ST elevation in other leads. ST elevation in aVR in conjunction with diffuse ST depression in precordial leads may be a sign of occlusion of very proximal portion of the left anterior descending artery.

\section{CASE PRESENTATION}

A 54-year old man, without previous history of ischemic heart disease referred to our hospital with crushing retroster-

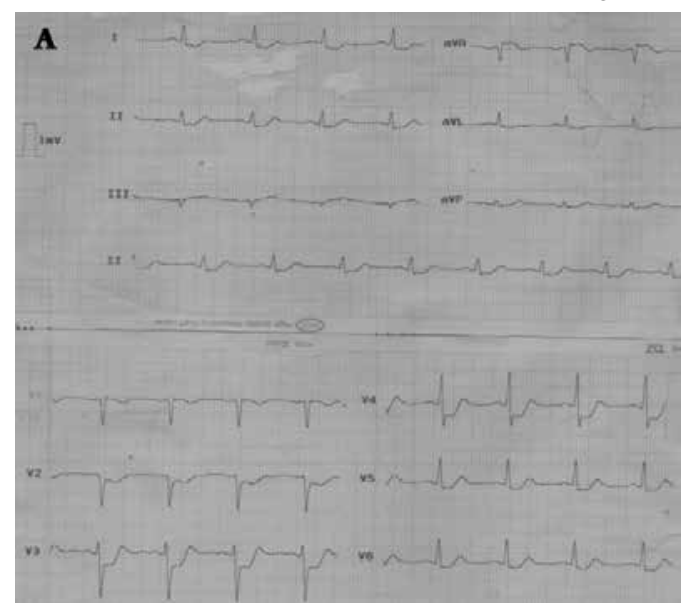

nal pain with radiation to lower mandible and cold sweating, from 3 hours before. 12 lead ECG revealed ST-segment elevation only in aVR lead and diffuse ST-segment depression in inferior, lateral and precordial leads. The patient was scheduled for emergent coronary angiography, which showed that left anterior descending (LAD) artery was cut off at very proximal portion and well-developed optus marginal (OM) artery was cut off at proximal portion with no ante grade run off. Urgent CABG was performed for the patient (LIMA on $\mathrm{LAD}$ and one SVG on OM).

The patient had no complication after CABG. Transthoracic echocardiography revealed ejection fraction of $40 \%$ and discharged one week later with ASA $80 \mathrm{mg}$ daily, atorvastatin $40 \mathrm{mg}$, captopril $12.5 \mathrm{mg}$ twice daily and carvedilol $6.25 \mathrm{mg}$ twice daily.

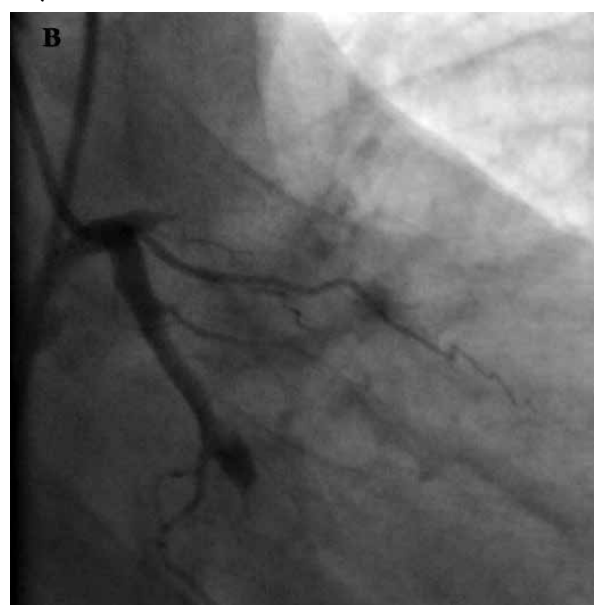

Figure 1: A, 12 lead ECG Revealed ST-segment Elevation Only in aVR Lead and Diffuse ST-segment Depression in Inferior, Lateral and Precordial Leads. B, Emergent Coronary Angiography Which Showed That Left Anterior Descending (LAD) Artery Was cut off at Very Proximal Portion and Well-developed Optus Marginal Artery Was Cut off at Proximal Portion With no Ante Grade Run off 


\section{DISCUSSION}

ST elevation in aVR lead has particular importance in ECG interpretation. This finding could be helpful in diagnosis of myocardial infarction due to left main coronary artery occlusion. However, this finding may be ignored in emergency units, especially in the absence of ST segment abnormalities like ST elevation in other leads $[1,2]$.

ST elevation in aVR in conjunction with diffuse ST depression in precordial leads may indicate occlusion of very proximal portion of the left anterior descending artery [3].

This is a challenging condition, particularly in centers that are not equipped for emergent coronary angiography and angioplasty. Therefore, the only therapeutic revascularization option is thrombolytic agent. On the other lead, complications of thrombolytic agents including bleeding catastrophes is not inevitable and it is a difficult and challenging decision to use thrombolytic agents in the setting of single ST-segment elevation in aVR lead and diffuse ST-segment depression in other leads. Last updated guidelines recommended class IIb for administration of thrombolytic in this challenging circumstance $[4,5]$.

As a conclusion, emergency clinicians and cardiologists should be familiar with the importance of ST-segment elevation only in aVR lead, especially in conjunction with diffuse ST segment depression in other leads, which could be indicative of $\mathrm{LAD}$ occlusion in the setting of myocardial infarction.

\section{ACKNOWLEDGMENTS}

There is no acknowledgment for the present study.

\section{CONFLICT OF INTEREST}

Authors declare that they have no conflict of interest.

\section{REFERENCES}

1. Gorgels AP, Engelen DJ, Wellens HJ. Lead aVR, a mostly ignored but very valuable lead in clinical electrocardiography. J Am Coll Cardiol. 2001;38:1355-6. http://www.ncbi.nlm.nih.gov/pubmed/11691507

2. Kuhl JT, Berg RM. Utility of lead aVR for identifying the culprit lesion in acute myocardial infarction. Ann Noninvasive Electrocardiol. 2009;14:219-25. http://www.ncbi.nlm.nih.gov/pubmed/19614632

3. Engelen DJ, Gorgels AP, Cheriex EC, De Muinck ED, Ophuis AJ, Dassen WR, et al. Value of the electrocardiogram in localizing the occlusion site in the left anterior descending coronary artery in acute anterior myocardial infarction. J Am Coll Cardiol. 1999;34:389-95. http:// www.ncbi.nlm.nih.gov/pubmed/10440150

4. Gaitonde RS, Sharma N, Ali-Hasan S, Miller JM, Jayachandran JV, Kalaria VG. Prediction of significant left main coronary artery stenosis by the 12-lead electrocardiogram in patients with rest angina pectoris and the withholding of clopidogrel therapy. Am J Cardiol. 2003;92:846-8. http://www.ncbi.nlm.nih.gov/pubmed/14516891

5. Hurst JW. Methods used to interpret the 12-lead electrocardiogram: Pattern memorization versus the use of vector concepts. Clinical cardiology. 2000;23:4-13. 